No of colonies per earpiece)

\begin{tabular}{|c|c|c|c|c|c|c|}
\hline \multirow[b]{2}{*}{ Micro-organisms cultured } & \\
\hline & 0 & $\begin{array}{c}\text { After } \\
\text { enrichment }\end{array}$ & $1-10$ & $11-20$ & $21-30$ & $>31$ \\
\hline Staphylococcus aureus ${ }^{\star}$ & 32 & & 7 & 1 & & 4 \\
\hline Other staphylococcus spp & 9 & 2 & 18 & 2 & 3 & 10 \\
\hline Aspergillus ${ }^{\star}$ & 42 & & 2 & & & \\
\hline Pseudomonas (not $P$ aeruginosa) & 43 & 1 & & & & \\
\hline Micrococcus & 42 & & 2 & & & \\
\hline Bacillus spp & 36 & & 7 & & & 1 \\
\hline Diphtheroids & 27 & & 7 & & & 10 \\
\hline Penicillium spp & 42 & & 2 & & & \\
\hline Clostridium perfringens & 42 & 2 & & & & \\
\hline Haemolytic streptococci (not & & & & & & \\
\hline$S$ pneumoniae) & 42 & & 2 & & & \\
\hline
\end{tabular}

^Potential pathogens

TABLE II - Methods of cleaning auriscope earpieces declared by general practitioners

\begin{tabular}{lc}
\hline Method & $\begin{array}{c}\text { No (\%) of } \\
\text { GPs } \\
(\mathbf{n}=85)\end{array}$ \\
\hline Alcohol swab & $31(36)$ \\
Soap and water & $24(28)$ \\
Antiseptic lotion & $16(19)$ \\
Cotton wool or tissue & $5(6)$ \\
Practice nurse's task & $5(6)$ \\
Other & $1(1)$ \\
No response & $3(4)$ \\
\hline
\end{tabular}

Cues that change general practitioners' behaviour include peer influence, literature reports, and financial inducements ${ }^{12}$ - none of these factors currently prompt general practitioners to consider cleaning their earpieces more assiduously. Once a cue has been received, an appraisal is made of the threats and benefits involved and of the advantages and disadvantages to be gained or lost. The threat of using uncleaned earpieces seemed slight, and improving hygiene was not perceived as carrying great benefit. Although some advantages were perceived from using clean earpieces (reducing infection, complying with patients' expectations of cleanliness), the perceived disadvantages were important ones (lack of time and the inconvenience, especially on home visits and at weekends). The health belief model thus suggests that there is little motivation for general practitioners to improve their auriscope cleaning behaviour.

\section{Conclusion}

A study directly assessing the risk of cross infection from using contaminated auriscope earpieces would be unlikely to gain ethical approval. However, this study may raise awareness that auriscope earpieces can harbour organisms that are potentially pathogenic. General practitioners may be alerted to change their behaviour by cleaning their earpieces more assiduously or using disposable ones.

Most general practitioners in the study used alcohol swabs to clean their earpieces, but this may not be an effective technique. Ayliffe recommends three methods: boiling earpieces in water for five to 10 minutes, five minutes' immersion in $70 \%$ alcohol, or autoclaving.' One manufacturer recommends that non-disposable earpieces should be boiled in distilled water for five minutes or autoclaved at $134-138^{\circ} \mathrm{C}$ for three minutes. Immersion in some cold disinfectant solutions may also be appropriate (see manufacturers' instructions), but phenolic and carbolic solutions should not be used, as these will damage the earpieces..$^{13}$ Disposable earpieces cost from $7 \mathrm{p}$ to $16 \mathrm{p}$ each, depending on the manufacturer and the quantity purchased. ${ }^{14}$

Ensuring clean earpieces for each patient will mean increases in workload, equipment, and expense. Clarification of the most appropriate and cost effective cleaning technique for auriscope earpieces in general practice is required.

We thank Professor G Ayliffe, Hospital Infection Research Laboratory, Dudley Road Hospital, Birmingham; the general practitioners of Airedale District Health Authority for their enthusiastic response; and Chris Evans for help with data analysis.

1 Ayliffe GAJ, Lowbury EJL, Geddes AM, Williams JD, eds. Control of hospital infection-a practical handbook. 3rd ed. London: Chapman and Hall, 1992.

2 Brook I. Bacterial flora of airline headset devices. Am f Otolaryngol 1985;6: $111-4$

3 Sheth KJ, Miller RJ, Sheth NK, Remeniuk E, Massanari RM. Pseudomonas aeruginosa otitis externa in an infant associated with a contaminated infant bath sponge. Pediatrics 1986;77:920-1

4 Marcy SM. Infections of the external ear. Pediatric Infectious Diseases 1985;4:192-201.

5 Stone M, Fulgham RS. Bactericidal activity of wet earwax. Ann Otol Rhinol Laryngol 1984;93:183-6.

6 Chai TJ, Chai TC. Bactericidal activity of earwax. Chemother 1980;18:638-41.

7 Cassini N, Cohn A, Davidson T, Witten BR. Diffuse otitis externa: clinical and microbiological findings in the course of a multicenter study on a new otic solution. Ann Otol Rhinol Laryngol 1977;86(suppl 39):1-16.

8 Marcy SM. External otitis due to infection. Pediatric infectious diseases 1985;4 (suppl 3):S27-30.

9 Lenette EH, Balows A, Hausler WJ, Truant JP. Manual of clinical microbiology. 3rd ed. Washington DC: American Society for Microbiology, 1980.

10 Roethlisberger FJ, Dickson WJ. Management and the worker: an account of a research program conducted by the Western Electric Company, Hawthorne Works, Chicago. Cambridge, Massachusetts: Harvard University Press, 1939.

11 Rosenstock IM, Kirscht JP. Why people seek health care. In: Stone GC Adler NE, eds. Health psychology: a handbook. San Francisco: Jossey Bass, 1979:161-88.

12 Horder J, Bosanquet N, Stocking B. Ways of influencing the behaviour of general practitioners. I $R$ Coll Gen Pract 1986;36:517-21.

13 Instruction leaflet for diagnostic instruments. London: Keeler Ltd, 1990.

14 "Practice Plus" diagnostic equipment catalogue. Leeds: DePuy Healthcare, 1992.

\title{
Stethoscopes as possible vectors of infection by staphylococci
}

\author{
Aodhan S Breathnach, David R Jenkins, Stephen J Pedler
}

Hand carriage of staphylococci by hospital staff is thought to be one of the main modes of spread between patients, ' and frequent handwashing to prevent such spread is emphasised in infection control measures. Stethoscopes, an almost universal tool of the medical profession, are an additional possible vector of infection as they touch many patients. Twenty years ago stethoscopes were shown to harbour staphylococci, ${ }^{3}$ yet standard sources on infection control still give no advice on cleaning these instruments. $^{45}$

We surveyed current practices of stethoscope hygiene among junior doctors in our hospital and assessed the degree of carriage of staphylococci by stethoscopes and the effect of cleaning on this.

\section{Methods and results}

Twenty nine doctors were questioned, and their stethoscopes were examined by moistening sterile swabs in saline, rubbing them over the diaphragm, and inoculating them on to blood agar, which was incubated aerobically overnight. Staphylococci were identified by standard methods.

We examined the effect of cleaning on 13 additional stethoscopes. One half of the diaphragm was swabbed and cultured; the diaphragm was then cleaned with a commercial saturated with alcohol swab (Sterets, Seton Prebbles Ltd) and allowed to dry; the other half of the diaphragm was then swabbed and cultured. Total colony counts before and after cleaning were noted.

Of the 29 doctors spoken to, only three had ever cleaned their stethoscopes, two intermittently and the other only once. None of the doctors could recall ever being advised in this matter.

Twenty six of the 29 instruments yielded staphylococci and the remainder were sterile. Most of the staphylococci were coagulase negative, but of the 29 stethoscopes five yielded $S$ aureus. The mean 


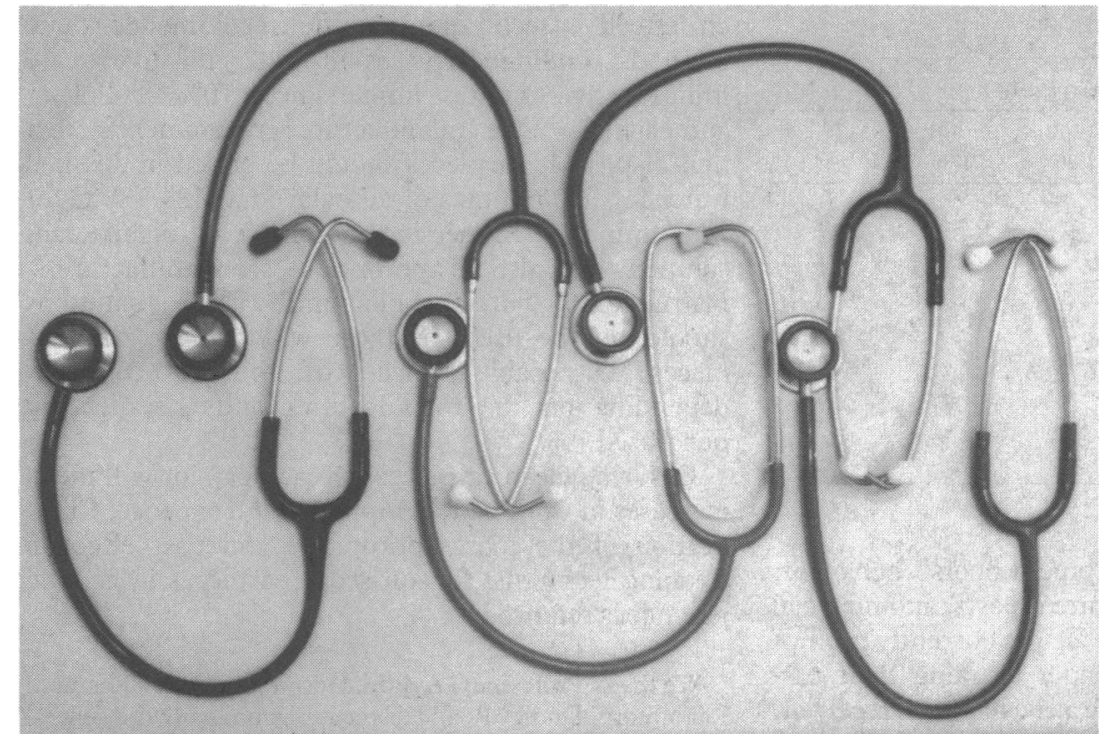

A breeding ground for staphylococci?

bacterial count was 69 (range 0-500) colony forming units per stethoscope.

Cleaning with an alcohol soaked swab was strikingly effective: six of the 13. stethoscopes had a bacterial count $>20$ colony forming units before cleaning (range 23-400); in these the mean reduction in the bacterial count after cleaning was $97 \%$ (range $87 \%-100 \%$ ).

\section{Comment}

These results confirm that doctors' stethoscopes are often contaminated with staphylococci and as such are a potential vector of infection. This contamination is greatly reduced by simple cleaning. Stethoscopes should be cleaned frequently as an adjunct to handwashing, especially in units where there are outbreaks of methicillin resistant $S$ aureus or where there are patients with increased susceptibility to staphylococcal infections.

Thompson RL, Cabezudo I, Wenzel R. Epidemiology of nosocomial infection caused by methicillin resistant Staphylococcus aureus. Ann Intern Med 1982;97:309-17.

2 Waldvogel FA. Staphylococcus aureus (including toxic shock syndrome). In: Mandell GL, Douglas RG, Bennet JE. Principles and practices of infections diseases. 3rd ed. Edinburgh: Churchill Livingstone, 1990:1489-508.

Gerken A, Cavanagh S, Winner HI. Infection hazard from stethoscopes in hospital. Lancet 1972; : 1214-5.

4 Aycliffe GA, Brumfitt W, Casewell MW, et al. Revised guidelines for the control of epidemic methicillin-resistant Staphylococcus aureus. I Hosp Infect 1990;16:351-77.

5 Aycliff GA, Lowbury EJL, Geddes AM, Williams JD. Decontamination of the environment, equipment and the skin. In: Control of hospital infection-a practical handbook. 3rd ed. London: Chapman and Hall Medical, 1992. 78-114.

\section{O little wolves of Leeuwenhoek}

Department of Primary Health Care, Whittington Hospital, London N19 5NF Susannah Kahtan, clinical lecturer

Department of Community Medicine, Mt Sinai School of Medicine, New York, NY 10029, USA

Morris Greenberg, visiting professor

Correspondence to: Dr $M$ Greenberg, 74 North End Road, London NW11 7SY.

BMF 1992;305:1574

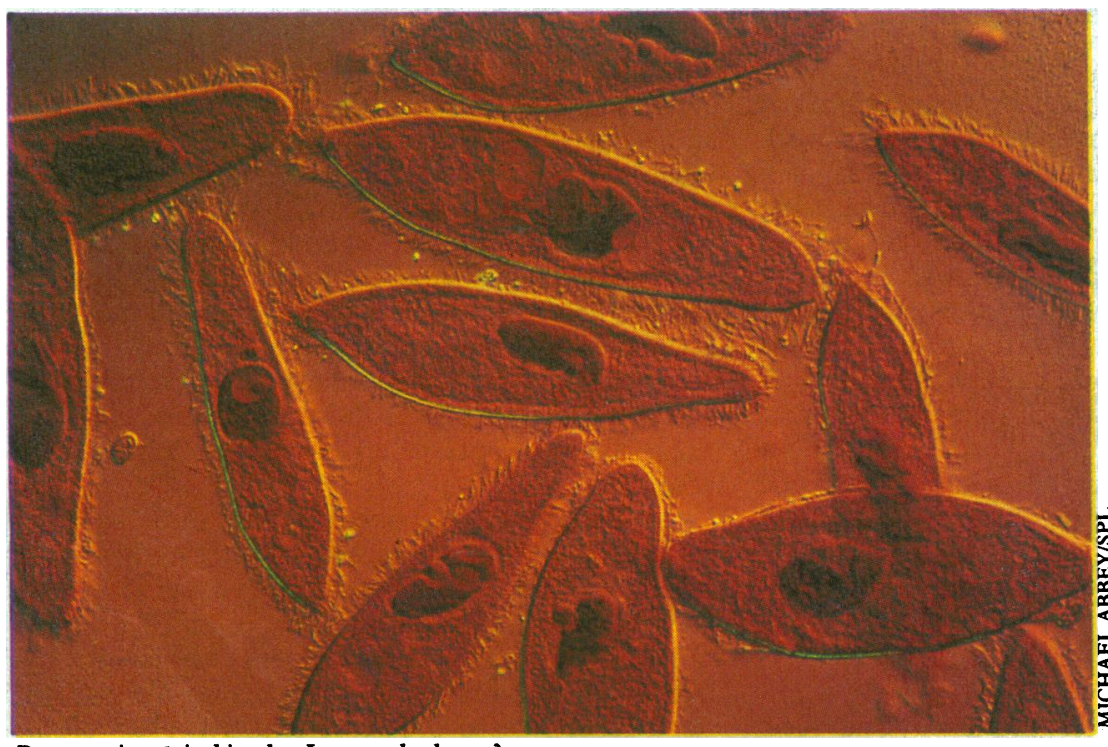

Paramoecium - is this what Leeuwenhoek saw?

\section{Susannah Kahtan, Morris Greenberg}

At the end of the seventeenth century, when the medical establishment ascribed all disease to an imbalance of the four humours, a brilliant mind proposed that one particular condition could be caused by "little wolves" so small that they could be seen only through his newly invented microscope. This brilliant mind did not belong to Robert Koch but to a Dutch amateur naturalist and lens maker, Anthony Leeuwenhoek. Most of us know Leeuwenhoek as the inventor of a microscope, but that was mere gadgetry; he deserves far more credit for one of the greatest eurekas in medical history.

Leeuwenhoek made his observations in 1692, while studying corn dust. He published his initial reports of "little wolves" in Dutch, without any press conference,

and only the perspicacity of Bernadino Ramazzini brought his work to the attention of the rest of Europe. Ramazzini was also interested in corn dust, believing it to be the cause of premature dropsy and death among sifters and measurers of grain. After discovering Leeuwenhoek's work, Ramazzini commented:

I have often wondered how so noxious a dust can come from grain as wholesome as wheat, and I began to suspect that in that dust there must lurk minute worms imperceptible to our senses and that they are set in motion by the sifting and measuring of the grain and broadcast by the air.... The great Anthony Leeuwenhoek records that with his microscope he observed in corn certain minute worms which he appropriately calls "wolves" [a term drawn from the science of alchemy, used to describe aggressive substances]. So we may well believe that it is a breed of worms that so grievously afflicts these workers.'

Ramazzini completed his work on occupational 윽 diseases in 1713; a Latin edition of Leeuwenhoek's o work describing the "wolves" had been published a $\frac{D}{2}$ few years before.

We do not agree, at present, that extrinsic allergic $\vec{N}$ alveolitis is caused by little wolves-or, as once $\underset{\omega}{\mathcal{N}}$ thought, paramoecium. This, however, should not $O$ detract from our appreciation of the inspiration that 0 forged the first link between inhaled small organic $\stackrel{\odot}{\Phi}$ particles and human disease. It has the flavour of a true $\stackrel{\mathcal{P}}{?}$ bite from the muse: a leap towards a new truth without 0 logical stepping stones. Later scientists like Jack Pepys made a chain that could bear the weight of sceptics, and $\stackrel{\odot}{\AA}$ they deserve full credit for this. An increasing number $\mathbb{\otimes}$ of agents derived from cereals and their flora and fauna has been shown to cause disease. But we should also remember Leeuwenhoek, in justice, and so that we $\frac{0}{0}$ bear in mind the possibility that great medical insights may come from non-medical people.

Ramazzini B. De morbis artificum. Padua: J B Conzattum, 1713. (Third edition; English translation published by Hafner, 1964.) 2 Van Leeuwenhoek A. Arcana naturae. Delft: letter, 1695:17. 